\title{
Out of hospital cardiac arrest (OHCA) patients without return of spontaneous circulation (ROSC) - should they be transported with ongoing resuscitation to the hospital?
} TW Lindner*, SA Hapnes and E Søreide

Address: Stavanger University Hospital, Stavanger, Norway

Email: TW Lindner* - litw@sus.no

* Corresponding author

from Scandinavian Update on Trauma, Resuscitation and Emergency Medicine 2009

Stavanger, Norway. $23-25$ April 2009

Published: 28 August 2009

Scandinavian Journal of Trauma, Resuscitation and Emergency Medicine 2009, I7(Suppl 3):O23 doi:I0.I I86/I757-724I-17-S3-O23

This abstract is available from: http://www.sjtrem.com/content/I7/S3/O23

(c) 2009 Lindner et al; licensee BioMed Central Ltd.

\section{Introduction}

We have previously reported high ROSC rates and excellent survival in OHCA in our region $[1,2]$. Prehospital emergency physicians (anesthesiologists) take active part in most resuscitation. If ROSC is not achieved, resuscitation is terminated on the scene in most cases. We want to investigate factors linked to survival in the few patients transported with ongoing resuscitation to the hospital.

\section{Methods}

Our EMS system has a catchment area of around 300000 inhabitants with one admitting hospital [2]. Using our Utstein template based quality assessment database for OHCA from the period from 1996 - 2005, we included OHCA of all causes, initial rhythm and ages, except patients with sudden infant death syndrome and with severe hypothermia.

\section{Results}

In the 10-year study period our EMS system responded to around 2050 alarm calls for OHCA. In around 1600 patients resuscitation was continued or started by the EMS, whereof $102(6 \%)$ patients were admitted to the hospital with ongoing resuscitation. None of these patients survived to discharge.

There was no significant change in age distribution over the 10-years study period. (Pearson correlation Figure 1). The age of the patients varies from 1 to 90 years.

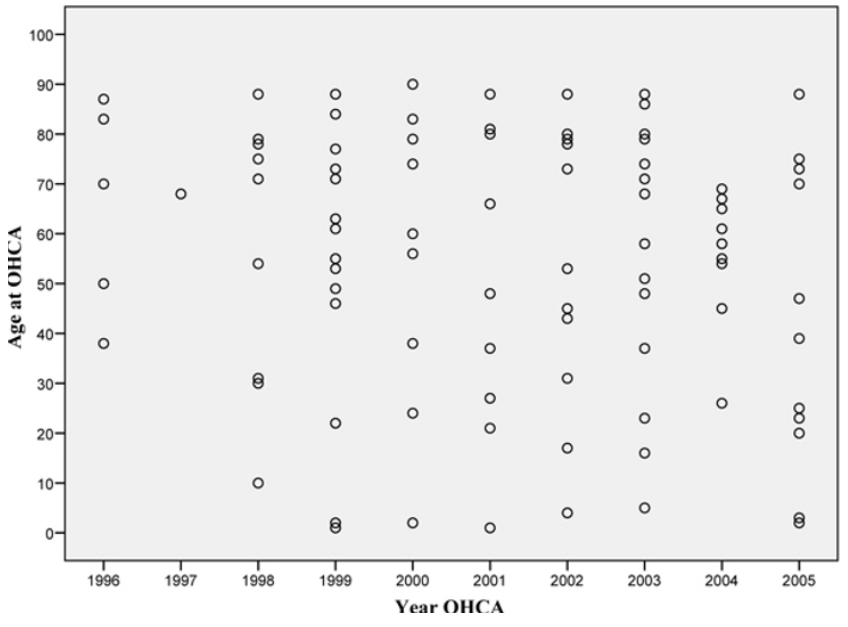

Figure I

Age distribution - Patients with ongoing resuscitation.

Of the 102 patients 25 had ventricle fibrillation (VF) as first rhythm. The median number of DC shocks was 10 . (Maximum 30 shock).

\section{Conclusion}

As none of the patients admitted to our hospital with ongoing resuscitation survived to discharge, we could not analyze factors linked to survival. Age did not seem to be a limiting factor when considering the continuation of resuscitation to the hospital. 
In the patients with VF as initial rhythm, a large amount of futile shocks were given. A study evaluating the benefit of early transferal to emergency percutaneous coronary intervention (PCI) with ongoing resuscitation might be worth conducting.

\section{References}

I. Busch M, Soreide E, Lossius HM, Lexow K, Dickstein K: Rapid implementation of therapeutic hypothermia in comatose out-of-hospital cardiac arrest survivors. Acta Anaesthesiol Scand 2006, 50(I0): 1277-83.

2. Langhelle A, Tyvold SS, Lexow K, Hapnes SA, Sunde K, Steen PA: Inhospital factors associated with improved outcome after out-of-hospital cardiac arrest. A comparison between four regions in Norway. Resuscitation 2003, 56(3):247-63.

Publish with Biomed Central and every scientist can read your work free of charge

"BioMed Central will be the most significant development for disseminating the results of biomedical research in our lifetime."

Sir Paul Nurse, Cancer Research UK

Your research papers will be:

- available free of charge to the entire biomedical community

- peer reviewed and published immediately upon acceptance

- cited in PubMed and archived on PubMed Central

- yours - you keep the copyright

Submit your manuscript here:

http://www.biomedcentral.com/info/publishing_adv.asp 